\title{
Correspondence on BIP Test
}

\section{To the Editor:}

I enjoyed reading the BIP test by Carden and Ori describing a modified loss of resistance technique for confirming epidural needle placement (1). In the modern era, even though interventionalists prefer to do all the procedures under fluoroscopy and deliver the medication target-specifically, we still depend on some of the old techniques to get to the target. One of these is interlaminar epidural injections, either in the lumbar epidural space, thoracic epidural space, or cervical epidural space. Since the initial description of Dogliotti (2), numerous techniques have been described to identify the epidural space without using too much air, saline, or contrast (1, 3-9).

Whenever there is false loss of resistance, the BIP test has been extremely useful in deciding whether we need to inject further contrast or look at a different view under the fluoroscopy. As the authors describe, even in an operating room with the use of fluoroscopy, it is extremely valuable. Since the publication of this article, I have heard many anesthesiologists specializing in interventional pain management describe various techniques and some have used similar techniques. However, this is the first time that I am aware of that it has been published as a BIP test. I was certainly not aware of this technique prior to this publication. I have always used either the sodium chloride solution or contrast to evaluate false loss of resistance under fluoroscopy. The BIP test has added another valuable aspect to my technique.

\author{
Vijay Singh, MD \\ Medical Director \\ Pain Diagnostics Associates \\ 1601 Roosevelt Road \\ Niagara, Wisconsin 54151 \\ President, \\ American Society of Interventional Pain Physicians \\ E-mail: vj@wmpnet.net
}

\section{References}

1. Carden E, Ori A. The BIP Test: A modified loss of resistance technique for confirming epidural needle placement. Pain Physician 2006; 9:323-325.

2. Dogliotti AM. Segmental peridural spinal anesthesia. Am / Surg 1933; 20:107118.

3. Kale SS, Oosthuysen SA. Identification of the epidural space using air with normal saline. Anaesthesia 2000; 55:615616.

4. Lin BC, Chen KB, Chang CS, Wu KC, Liu YC, Chen CC, Wu RS. A 'membrane in syringe' technique that allows identification of the epidural space with saline while avoids injection of air into the epidural space. Acta Anaesthesiol Sin 2002; 40:55-60.

5. Michel MZ, Lawes EG. Identification of epidural space by drip method. Reg 8 . Anesth 1991; 16:236-239.

6. Bhate $\mathrm{H}$. Identification of the peridural space with the infusion method in relation to the incidence of inadvertent puncture of the dura. Reg Anaesth 9 . 1984; 7:44-47.

7. Lechner TJ, van Wijk MG, Maas AJ, van Dorsten FR, Drost RA, Langenberg CJ, Teunissen LJ, Cornelissen PH, van Niekerk J. Clinical results with the acoustic puncture assist device, a new acoustic device to identify the epidural space. Anesth Analg 2003; 96:11831187.

Lewis MP, Thomas P, Wilson LF, Mulholland RC. The "Whoosh" test. A clinical test to confirm correct needle placement in caudal epidural injection. Anaesthesia 1992; 47:57-58.

Howell TK, Prosser DP, Harmer M. A change in resistance? A survey of epidural practice among obstetric anaesthetists. Anaesthesia 1998; 53:238243.

\section{TO THE EDITOR:}

The small advances in clinical science are often some of the most important to the clinical practitioner and Drs Carden and Ori (1) have made a worthy contribution regarding their modification of the loss of resistance technique in locating the posterior epidural space. A few comments are proffered:

It is noted the authors state the technique "may be used where single shot epidurals are being given without fluoroscopy." This would include the frequently employed non-fluoroscopically guided interlaminar epidural steroid injection. However there are important clinical differences in the administration and subsequent confirmation of the effect of a single shot analgesic/anesthetic and an epidural steroid injection.

The loss of resistance technique is used as an initial approximation of the epidural space for anesthesia/ analgesia via single shot and catheter techniques, and 